\title{
DISSOLUÇÕES NECESSÁRIAS: A PERSPECTIVA DOS HUPD’ÄH NAS RELAÇÕES DO "SISTEMA REGIONAL DO ALTO RIO NEGRO"
}

\author{
BRUNO RIBEIRO MARQUES 1 \\ INSTITUTO SOCIOAMBIENTAL, BRASIL
}

DANILO PAIVA RAMOS ${ }^{2}$

$U F B A, B R A S I L$

\begin{abstract}
RESUMO: Procurando ancorar-se na perspectiva dos Hupd'äh do campo relacional interétnico do Alto Rio Negro-Uaupés, o presente artigo analisa o chamado "viés tukano", ângulo que privilegia a socialidade de dados coletivos sociais da região em detrimento de outros, e seu impacto para o modo como os Hupd'äh e os povos da família linguística Naduhup figuram no "sistema regional rionegrino". Para tanto, estabelece-se o paralelo entre, de um lado, narrativas míticas e princípios do pensamento hup e, de outro, o discurso cientifico etnológico que sedimenta o "grande divisor" composto pelos "indios do rio" e "indios do mato". Em que medida o ponto de vista Hup sobre o "sistema regional" revela pontos cegos do modelo sociológico e aponta novos caminhos para a reflexão acadêmica sobre as dinâmicas sociais regionais?
\end{abstract}

PALAVRAS-CHAVE: Teoria Antropológica; Alto Rio Negro - Uaupés; Hupd'äh; Grande Divisor

\begin{abstract}
Hupd'äh people's point of view of their position in the interethnic and relational field of Upper Rio Negro-Uaupés is crucial to rethink the so called "Upper Rio Negro social system". Scientific discourse focused on rionegro indigenous societies is marked by the "bias tukano". This "bias" privileges certain kinds of social collectivities over others and has a negative impact on Hupd'äh and Naduhup peoples academic representations in the "rionegrovaupés regional social system". Seeking to highlight some theorethical consequences of this "Great Divide", we take into account mythical narratives and hup theoretical concepts, from one side, and the Great Divide: "river people" and "forest people" that structures the ethonological scientific discourse, from the other. Could the Hupd'äh people's point of view about the "regional system" reveals some of the sociological model blind spots and open new ways to academic reflection on this regional social dynamics?
\end{abstract}

KEYWORDS: Anthropological Theory; Alto Rio Negro - Uaupés Region; Hupd'äh; Great Divide

\footnotetext{
${ }^{1}$ Doutor em Antropologia Social (Universidade Federal do Rio de Janeiro / Museu Nacional, Brasil) e pesquisador do Instituo Socioambiental, Brasil. E-mail: bmarques23@gmail.com

2 Professor do Departamento de Antropologia e Etnologia (Universidade Federal da Bahia, Brasil), e assessor da Federação de Organizações Indígenas do Rio Negro (FOIRN) e da Fundação Nacional do Índio (FUNAI). E-mail: dpaivaramos@gmail.com

MARQUES, Bruno Ribeiro; RAMOS, Danilo Paiva. Dissoluções necessárias: a perspectiva dos Hupd'äh nas relações do "sistema regional do Alto Rio Negro". Espaço Ameríndio, Porto Alegre, v. 13, n. 2, p. 104-131, jul./dez. 2019.
} 
"...atingir um limiar, sem dúvida o mais proveitoso para as sociedades humanas, em que se instaura um justo equilíbrio entre sua unidade e sua diversidade; e que mantém no mesmo nível a comunicação, favorável às iluminações recíprocas, e a ausência de comunicação, igualmente salutar - pois as frágeis flores da diferença precisam de meia-luz para subsistir."

(Claude Lévi-Strauss)

Ao professor Ricardo Goes Pires (Em memória)

\section{Introdução}

Em 2016, num Seminário de Educação Hupd'äh e Yuhupdeh no âmbito do desenvolvimento do Plano de Gestão Territorial e Ambiental da Terra Indígena Alto Rio Negro (PGTA - Alto Rio Negro), professores e lideranças Hupd'äh e Yuhupdeh explicitaram seu incômodo com o modo como os trabalhos acadêmicos e as instituições atuantes na região referem-se ao conjunto de seus povos e à sua família linguística, designando-os como "Maku". Após discussões com assessores educacionais, linguistas e antropólogos, uma votação e a deliberação de que uma consulta pública fosse conduzida ao longo do desenvolvimento do PGTA, os presentes apontaram os nomes Naduhup ou Naduhupy, formados pela aglutinação de palavras para "gente" e "humanos" em cada uma das línguas da família, como um modo provisório de começar a solucionar o impasse.

Como ficará claro a seguir, há grande incômodo com o caráter pejorativo do termo "Maku", utilizado pelos pesquisadores na tentativa de agregar diversas etnias a partir de certa homogeneidade de traços. Num trabalho recente, Pedro Lolli (2016) aborda a "plasticidade Maku",

\footnotetext{
3 A elaboração do PGTA - Alto Rio Negro é coordenada pela FOIRN (Federação das Organizações Indígenas do Rio Negro), pelo ISA (Instituto Socioambiental) e pela FUNAI (Fundação Nacional do Índio). Por serem considerados "povos de recente contato" pela FUNAI e devido a algumas especificidades logísticas de acesso aos seus grupos locais, foram realizados, de forma complementar, alguns trabalhos específicos com os Hupd'äh e Yuhupdeh dentro deste Plano que contempla todos os povos da região. Este Seminário de Educação foi coordenado pela profa. Beatriz Stumpf, e foi parte do Projeto de Extensão "Fortalecendo Escolas Indígenas Hupd'äh, Yuhupdeh e Dâw”, do Instituto Federal do Amazonas (IFAM), Campus São Gabriel da Cachoeira / Núcleo Gestor de Estudos Linguísticos e Antropológicos (NUGLAN), em parceria com a Secretaria Municipal de Educação e Cultura de São Gabriel da Cachoeira (SEMEC), a FUNAI, a FOIRN e membros do Coletivo de apoio aos povos Yuhupduh e Hupd'äh (CAPYH). A insatisfação dos Hupd'äh e Yuhupdeh com a designação científica "Maku” foi expressa em um evento para discutir educação escolar também no ano de 2008. Conforme Renato Athias, durante a realização do Curso de Magistério Indígena Paah Sak Tëg, as propostas de modificação do nome da família linguística para "Uaupés-Japurá" e "Nadahup" foram levadas ao conhecimento dos Hupd'äh, Yuhupdeh e Dâw presentes, que não as aprovaram, não chegando, entretanto, a um consenso sobre qual deveria ser, então, o termo de referência que os agrupasse.
} 
enfatizando a heterogeneidade do uso do termo pelos estudos antropológicos e linguísticos sobre povos da região. Para o autor, a definição do uso do termo foi consolidada principalmente pelos trabalhos etnográficos que visavam a identificar traços comuns aos povos assim chamados. Lolli (2016) aponta para um encaixe entre o modelo sociológico das sociedades de caçadores-nômades e discurso indígena que caracterizava tais povos como "bons caçadores", "habitantes do mato como animais", "feiticeiros poderosos". Ao longo das últimas décadas de produção acadêmica, o uso do termo "Maku" teve seguimento, ainda que os pesquisadores tenham reiteradamente chamado a atenção para o modo como tal nome era percebido negativamente pelos assim designados, e para a inadequação de conceituar tais grupos como "escravos" (p.190). O autor aborda também como a plasticidade do uso do termo se deslinda entre diferentes povos indígenas da região e no interior de um mesmo povo, sendo, via de regra, o marcador de uma relação não necessariamente substancializada como um etnônimo ou um classificador sociológico fixo. Mas, o que temos em vista como objeto do presente artigo é uma outra dimensão, a qual diz respeito ao modo como a distinção índios do mato / índios do rio foi incorporada na literatura etnológica na forma de um "grande divisor", tendo efeitos duradouros, algo que, é interessante notar, persiste na literatura etnológica e têm desdobramentos para além dela. Além disso, a consciência deste problema não necessariamente evita a reprodução de seus mecanismos concretos.

Em sentido introdutório, cabe referir que desde Die Maku, KochGrünberg (1906/ 2010), ao utilizar o termo "Makú", afirma que essa palavra se origina das línguas arawak, constitui uma grave injúria e é uma forma de referir-se a grupos indígenas específicos que, para ele, teriam como marca contrastiva o fato de serem nômades (Koch-Grünberg, $1906 / 2010$, p. 29). Através de um estudo minucioso dos textos de cronistas, Becerra, Calvo e Rubio (1996-1997) reconstituem historicamente os usos do termo Maku, que aparece já em documentos do século XVII através do termo genérico "macos", referindo-se a órfãos trocados entre grupos locais e depois comercializados com europeus, e a escravos indígenas da região do Alto Orinoco (Becerra, Calvo e Rubio, 1996-1997, p. 100). Para os autores, o emprego do termo "Makú" nos séculos XVII e XVIII teria como referência o sentido de "sem parente" ou de "apartado de seu grupo". Os grupos derrotados nas batalhas contra os europeus ou capturados por outros grupos indígenas, eram chamados de "maco", aqueles que começaram a constituir a mão de obra escrava. Em meio à exploração da borracha por comerciantes e à ativação do sistema escravista na região do Uaupés, aqueles que eram vistos como inferiores se transformaram em escravos vendáveis, passíveis de captura, denominados "Maku” (Becerra; Calvo; Rubio, 1996-1997, p. 102). Como conta Münzel (1969), grupos Maku eram ora recrutados para caçar e apresar índios de outros grupos, ora vítimas nessas "caçadas aos escravos", fomentadas pelos comerciantes e patrões da borracha. Mais 
tarde, os pesquisadores mostrarão que a palavra Maku, hoje corrente na literatura científica regional, origina-se das línguas arawak e significa "sem língua" (ma = privativo e aku = palavra) (Journet, 1995; Athias, 1995; Becerra; Calvo; Rubio, 1996).

Os Hupd'äh habitam a região do Alto Rio Negro (AM) na fronteira entre o Brasil e a Colômbia. No Brasil, habitam mais de vinte comunidades e algumas dezenas de sítios no interior da floresta, distribuídos pela área interfluvial dos rios Tiquié e Papuri, ambos afluentes da margem direita do rio Uaupés. O último censo realizado apontou uma população de 2.634 indivíduos (FOIRN e ISA, 2017). Seguindo a classificação proposta por Reid (1979) e Pozzobon (1983), os Hupd'äh no Brasil estão distribuídos em três grupos regionais: 1) ocidental, entre os altos cursos dos rios Papuri e Tiquié; 2) central, entre os médios cursos desses rios; e 3) oriental, entre o baixo Papuri e o médio Uaupés, tendo o igarapé Japu como referência. Os grupos regionais hup apresentam diferenças dialetais entre si e são de tendência endogâmica, formando um conjunto de comunidades em processos de visitação e troca intensos; além disso, os modos como os impactos da colonização se colocaram em cada um deles também varia.

A língua Hup pertence à família linguística Naduhup, junto às línguas Yuhup, Dâw e Nadëb (Epps \& Bolaños, 2017). A alta mobilidade e circulação pelo território são aspectos fundamentais do modo de vida hup, que estão relacionados ao vasto conhecimento que possuem sobre os caminhos, os igarapés, os animais e a vegetação local. Associada à mobilidade, a caça-coleta constituiu-se como foco de interesse das pesquisadas antropológicas sobre esse povo que estabeleciam o contraste entre os Hupd'äh com as populações ribeirinhas de pescadoresagricultores (Athias, 1995; Reid, 1979; Pozzobon, 1991; SilverwoodCope, 1990). A estrutura social hup tem nos clãs agnáticos seus segmentos básicos de constituição e de diferenciação. O casamento preferencial dá-se entre os primos cruzados bilaterais numa mesma geração e procura respeitar certa hierarquia entre os clãs. Em contraste com outros povos da região, o sistema de matrimônio dá-se segundo a endogamia linguística e a exogamia clânica. A coabitação em um mesmo território ou espaço de grupos familiares gera os grupos locais, que são nomeados e diferenciados entre si (Reid, 1979; Athias, 1995).

Esses traços aproximam os Hupd'äh de povos como os Yuhupdeh, Nadëb, Dâw, Kákwa e Nukák, e levaram a literatura etnológica da região a designa-los como povos Maku. Além dos conjuntos hoje referidos como Naduhup e Kakua-Nukak ${ }^{4}$, o sistema regional do Alto Rio Negro, também denominado sistema uaupesiano, é composto por povos pertencentes às famílias linguísticas Tukano oriental (Tukano, Wanano, Pira-Tapuio, Arapaso, Bará, Tuyuka, Pisamira, Desana, Siriano, Tatuyo, Karapana, Barasana, Yeba Masã, Makuna, Taiwano, Cubeo, Tanimuka, Letuama,

\footnotetext{
${ }^{4} \mathrm{~A}$ partir de estudos linguísticos intensivos e de uma crítica sistemática aos estudos anteriores, os trabalhos de Bolaños \& Epps (2017), Bolaños (2010) e Bolaños \& Epps (2017) propõem que as línguas anteriormente classificadas como pertencentes à família Maku-Puinave configuram, na verdade, duas famílias distintas: Naduhup (Hup, Yuhup, Dâw e Nadëb); e Kákua-Nukak (Kákua e Nukak).

MARQUES, Bruno Ribeiro; RAMOS, Danilo Paiva. Dissoluções necessárias: a perspectiva dos Hupd'äh nas relações do "sistema regional do Alto Rio Negro". Espaço Ameríndio, Porto Alegre, v. 13, n. 2, p. 104-131, jul./dez. 2019.
} 
Yuruti, Yuana, Mirití-tapuya) e Arawak (Tariana, Baniwa, Wakuenai, Curripaco, Warekena, Kabiyari, Yukuna e Matapí). Há também os Baré, originalmente Arawak, mas atualmente falantes de Nhengatú (língua geral - língua da família Tupi); e os Carijona sobreviventes de um povo de língua Karib (Cayón \& Chacon, 2014). Entendendo haver um sistema relativamente homogêneo baseado na exogamia linguística, nas relações hierárquicas rituais e territoriais entre povos falantes de línguas Tukano e Arawak, os pesquisadores descrevem a especificidade da articulação dos povos ditos Maku a esse "sistema rionegrino ou uaupesiano" (S. HughJones, 1979; C. Hugh-Jones, 1979; Cayón \& Chacon, 2014).

Stolze Lima (2005) salienta que as discussões sobre as formas de organização social nas terras baixas sul-americanas realizadas nas décadas de 1970 e 1980 imputam uma imagem de fluidez em relação a algumas sociedades ameríndias. Tais discussões partem do debate geral acerca da aplicabilidade dos conceitos de estrutura social da antropologia social britânica baseada no material etnográfico sobre povos africanos. De um lado, constituiu-se uma linha de argumentação que opera o contraste entre um conjunto de sociedades fluidas ou amorfas - dentre elas os Piaroa e Caribe da Guiana e os Tupi em geral - e um conjunto de sociedades fundadas em estruturas sociais complexas - assim, os Jê Bororo do planalto centro-brasileiro, bem como os Tukano do Noroeste Amazônico (Lima 2005: 83-4). Tendo como referência esse quadro geral, os estudiosos dos povos do Alto Rio Negro parecem ver a socialidade multiétnica da região como consolidada a partir da complexidade Tukano, em que a hierarquia clânica, a exogamia linguística e a mitopolítica da cobra-canoa delineiam os contornos de um sistema social regional. Desviantes quanto a esses padrões, os povos Naduhup são descritos sob os signos do igualitarismo, da fluidez estrutural, do improviso, o que os sedimenta como parte do conjunto de sociedades amorfas, fluidas e igualitárias (conforme amplamente descrito em Marques, 2009).

O objeto do ensaio é eminentemente bibliográfico, mas cabe referir que o contexto em que se coloca diz respeito a processos recentes na vida desses povos, os quais acabaram colocando para as instituições atuantes na região problemas análogos aos que enfrentamos na literatura etnológica. Além disso, para a crítica bibliográfica, lançamos mão de dados etnográficos. O presente trabalho tem como foco o estudo dos efeitos conceituais e políticos que o fraseamento da participação dos Hupd'äh na socialidade multiétnica do alto rio Negro implicam até hoje. Tomando em paralelo o discurso científico, que consolidou o modelo sociológico do "sistema regional do Alto Rio Negro", e o ponto de vista dos Hupd'äh expresso por meio de mitos e teorias da alteridade, procurase entender de que modo se constituiu o chamado "viés tukano" (bias tukano) que sedimenta o modelo sociológico comparativo a partir de um "grande divisor" fundado em uma forma particular de opor "índios do rio" e "índios do mato". Os guias neste caminho são os próprios Hupd'äh, seus modos de diferenciação e individuação cosmopolíticas e suas recentes descidas massivas para a cidade de São Gabriel da Cachoeira (AM) em busca da obtenção de documentos e do acesso aos programas sociais do 
governo brasileiro. Descidas essas que passaram a colocar sua presença, de um modo até então inaudito, para uma série de atores políticos locais, dentre lideranças das organizações indígenas, instituições públicas, financeiras e figuras da política local em geral. Em que medida, o ponto de vista Hupd'äh sobre seu posicionamento ativo no campo relacional multiétnico rionegrino evidencia os pontos cegos do modelo sociológico do "sistema regional rionegrino" que situa esse e os demais povos Naduhup (Yuhupdeh, Dâw e Nadëb) como desviantes quanto ao padrão Tukano e Arawak?

\section{A "política" e a formação do sistema regional do alto rio Negro: perspectivas e assimetrias}

Em um artigo de 2012, S. Hugh-Jones chama a atenção para o modo como a mito-história do Alto Rio Negro pode ser vista como uma história política num duplo sentido. Por um lado, reflete a resistência dos grupos locais à dominação externa e legitima as reivindicações indígenas por territórios. Por outro lado, as histórias de cada povo legitimam suas próprias reivindicações territoriais e suas posições de status perante os demais grupos. Dentre os diversos temas sobre os quais versam as narrativas míticas para a composição dessa história política, destaca-se o motivo da Viagem na Cobra-Canoa pelo Rio de Leite. Esse tema mítico, tão presente nas análises sobre a mitologia e vida ritual dos povos Tukano, não teve a profundidade analítica nem suas consequências devidamente desdobradas na literatura etnológica sobre os povos da família linguística Naduhup, sendo apenas aludido nos trabalhos de Reid (1979) e de Pozzobon (1991).

O registro recente de narrativas míticas e enunciados xamânicos que trazem o motivo da Viagem na Cobra-Canoa como fundamental para estabelecer marcadores diacríticos interétnicos (Hupd'äh / povos Tukano) (M1) aponta para a relevância de enfocar o modo como a mito-história rionegrina e a história política da região são elaboradas a partir da perspectiva hup. Através da contraposição de narrativas míticas e xamânicas a formulações da literatura etnológica da região, que engendram uma espécie de "teoria da dominação", tendo como condição um certo dualismo "índios do rio versus índios do mato", será possível perceber de que modo os grandes divisores científicos consolidam uma mito-história e um sistema social regional no qual os Hupd'äh fazem parte, via de regra, como um "antiexemplo de civilização", um contraste desviante daquilo que vai se consolidando como um padrão marcado pela norma, pela fixidez, pela hierarquia ranqueada e pelos rituais elaborados (Pozzobon, 2011).

\footnotetext{
${ }^{5}$ Embora, vale notar, Mario Terribilini, que passou três semanas entre os Hupd'äh do Japu em 1960, quando trata da mitologia dos Hupd'äh já se referia da seguinte forma: "pour arriver où ils sont maintenant, ils remontèrent le rio en suivant un grand serpent (Hi-Bachmê). Les Makús sont les fils de ce grand serpent, qu'ils adorent encore" (2000: 241). Possivelmente seja uma referência à / Hib'áh M'éh /, "Cobra do Nascimento".

MARQUES, Bruno Ribeiro; RAMOS, Danilo Paiva. Dissoluções necessárias: a perspectiva dos Hupd'äh nas relações do "sistema regional do Alto Rio Negro". Espaço Ameríndio, Porto Alegre, v. 13, n. 2, p. 104-131, jul./dez. 2019.
} 
É refletindo sobre a própria noção de "política" que a narrativa apresentada por Ricardo Dias Pires (falecido recentemente), professor e Agente Pedagógico Indígena (API), ajuda a entender a importância da temática da Cobra-Canoa para a diferenciação dos coletivos Hupd'äh e Tukano no interior do chamado "sistema rionegrino".

\section{M1. A política da Cobra-Canoa}

No magistério, muitos Tukano contaram da história da Cobra-Grande dizendo que eles tinham saído primeiro. Política. Mas a verdade é que os Hup tinham saído primeiro. Foi o Hupd'äh quem saiu primeiro da Cobra-Grande. Os Tukano dizem que foram eles, mas não é verdade, não. Porque esses Hupd'äh, Dâw, eles foram timoneiros.

Saíram lá do Lago-de-Leite no Rio de Janeiro e vieram dar aqui. Primeiro foram ali pra Ipanoré. Depois foram indo lá pra o Papuri, Iauaretê, e deixando os povos. Os Hupd'äh ficavam ali no rio Turi e daí foram descendo, porque todos os povos vieram como peixes dentro da Cobra, mas quando chegaram nos seus lugares eles já saíam e transformavam em gente.

Os Tukano falam muita coisa diferente do caminho da Cobra, por onde ela foi primeiro, depois. É política, né. Falam que os Hupd'äh saíram depois. Política. (Ricardo, 13/05/2009, transcrição de fala).

A história surgiu em meio a uma conversa sobre o magistério indígena, quando os Tukano narram a viagem na Cobra-Canoa, afirmando sua saída anterior. Essa forma tukano de contar é tida como sinônimo de "política"; uma "política", no caso, que subsume a importância dos Hupd'äh terem saído primeiro da Cobra-Grande. A explicação mostra os Hupd'äh e os Dâw como timoneiros, aqueles que conduziram a Cobra em sua jornada do Lago-de-Leite, no Rio de Janeiro, até a Cachoeira de Ipanoré. Timoneiro assume o sentido daquele que guia, que governa a embarcação por conhecer o caminho. A posição dos Hupd'äh está presente em algumas narrativas tukano, mas equacionada, em geral, à qualidade de ajudantes ou servos da humanidade tukano. Em língua Hup, esse sentido será expresso pela palavra /kih sät/, "guia, mentor", aquele que vai à frente mostrando os caminhos, aquele que inicia à ação. $\mathrm{O} / \mathrm{kih}$ sät/ é seguido pelos /uy ham däh/, "acompanhantes" ou "seguidores", aqueles que vão atrás. Essa posição, entretanto, é situacional, depende da composição do coletivo em deslocamento e de uma avaliação complexa sobre o conhecimento do percurso, da precedência etária, da senioridade clânica e da expectativa dos demais de que alguém seja o "guia". Assim, como guias a conduzir a embarcação, Hupd'äh e Dâw assumem posições num campo de relações que evidenciam seus saberes, habilidades e atributos necessários para estarem à frente e diferenciaremse de seus "seguidores", peixes que formariam a humanidade tukano. 
Como está amplamente exposto nos trabalhos etnográficos produzidos na região ao longo do século XX, os relatos que os Tukano fazem dos povos da família linguística Naduhup (designados como Maku) no mais das vezes giram em torno de figuras que transitam no contínuo entre natureza e cultura: subumanos, canibais, incestuosos, índios selvagens, sem conhecimentos rituais e mitológicos, enfim, fundamentalmente, sem cultura (Århem 1989: 10). O princípio da exogamia linguística ao mesmo tempo articula as relações entre os diversos grupos exogâmicos tukano da região do Uaupés - em um sistema regional baseado no casamento entre falantes de línguas diferenciadas - e implica a exclusão dos povos da família linguística Naduhup (cada qual linguisticamente endogâmico), pela imagem de antihumanidade atribuída desde a perspectiva tukano. A endogamia linguística seria um dos sinais diacríticos determinantes da oposição entre eles e os índios ribeirinhos, sendo o leitmotiv da imagem de antihumanidade atribuída aos habitantes do interior das florestas, convertendo-se num traço incestuoso desde a perspectiva dos Tukano.

Atualmente, entretanto, esses cortes tendem a não ser marcados de forma tão intensa nas distinções interétnicas. Devido às transformações no modo de vida dos indígenas do alto rio Negro em decorrência da missionarização dos salesianos - bem como, da parte do movimento indígena, da adoção de um ideal que busca melhores condições de vida para os povos da região, tendo no horizonte justamente a igualdade de condições -, as imagens de subhumanidade foram decerto atenuadas. Embora, importante reafirmar, não se reduza a uma questão de doutrina religiosa, há, em alguma medida, uma inflexão católica dessas imagens, variando para os temas da "compaixão", da "pena" e de uma disposição a "ajudar" os Hupd'äh a acederem aos deveres e benesses de um modo de vida mais integrado à escola, aos serviços de saúde do Estado, ao aprendizado da língua portuguesa e à produção agrícola ou de artesanato com vistas à geração de renda. Ainda assim, o caráter intempestivo e potencialmente agressivo dos Hupd'äh nos dias de festa com consumo de caxiri é constantemente lembrado - "eles são bons, tranquilos, mas quando bebem..." -, trazendo à tona uma vez mais os signos de outrora, além de sua reputada inconstância nos labores produtivos da roça. A esse aspecto, os Tukano acrescentam que, quando coordenados por alguém que os conhece, que sabe como mandar neles, um verdadeiro chefe, eles tendem a se tornar produtivos, verdadeiros trabalhadores, o que definitivamente não ocorreria quando abandonados à própria sorte.

Do ponto de vista dos Hupd'äh, é preciso cuidado e atenção ao interagir com os Wòhd'äh ${ }^{6}$, dada a presença excessiva de energia quente

\footnotetext{
6 "Wòhd'äh" é o termo pelo qual os Hupd'äh se referem aos demais indígenas da região com os quais têm contato, que não os Yuhupdeh, Kakwa e Dâw, isto é, todos exceto os que os Wòhd'äh, por sua vez, chamam de "Maku". Importante notar que os Baniwa e Baré não são englobados nessa categoria, embora, do ponto de vista hup, guardem semelhanças com os Wòhd'äh. Isto é, paradigmaticamente, o termo Wòhd'äh se refere aos povos da família linguística Tukano oriental. Para indicar o ponto de vista hup do sistema, lançamos mão desta categoria, tão generalista quanto o termo "Maku", cuja enunciação é alternativamente uma marca do ponto de vista tukano. Wòhd'äh é uma categoria frequentemente traduzida como "índios" pelos Hupd'äh, numa lógica em que, da perspectiva hup, na região existiriam os Hupd'äh, os índios MARQUES, Bruno Ribeiro; RAMOS, Danilo Paiva. Dissoluções necessárias: a perspectiva dos Hupd'äh nas relações do “sistema regional do Alto Rio Negro". Espaço Ameríndio, Porto Alegre, v. 13, n. 2, p. 104-131, jul./dez. 2019.
} 
e agressividade em seus corpos. Atitudes arbitrárias, a altivez, a compulsão em mandar, a inabilidade para caminhar pela mata ou para caçar, por exemplo, são aspectos que aderem à imagem atribuída pelos Hupd'äh aos Wòhd'äh. Além de violentos e agressivos, os Wòhd'äh, mais concentrados no universo ribeirinho, desconheceriam saberes fundamentais imanentes às paisagens e ouvidos nas interações com animais e espíritos que habitam as moradas ao longo das trilhas. Os Wòhd'äh teriam chegado depois às terras do Uaupés e, mais recentemente, conforme a narrativa de uma das comunidades dos Hupd'äh, teriam sido impelidos, pelos feitiços praticados contra eles, a deixar suas comunidades e migrar para a cidade de São Gabriel. São, enfim, vistos como pessoas, em certo sentido, fracas por não dominarem a agressividade que degenera no "autoritarismo" com que tratam os Hupd'äh, o que contemporaneamente desdobra-se ainda em uma crítica adicional feita pelos Hupd'äh a respeito de alguns projetos dos Wòhd'äh para a geração de renda no interior da mata. "Os Wòhd'äh são como colonizadores", disse, em português, um homem Hupd'äh do igarapé Japu.

Ainda neste âmbito, a recente intensificação da relação dos Hupd'äh com o dinheiro, acessado pelos velhos aposentados e pelos beneficiários de programas sociais do governo federal, tem causado tensões devido ao papel mediador que alguns Wòhd'äh estabelecem entre os beneficiários Hupd'äh e os comerciantes de São Gabriel da Cachoeira. Por vezes, inclusive, o próprio Wòhd'äh é o comerciante, como ocorre em lauaretê e, em alguns casos, também em São Gabriel da Cachoeira. A respeito disso, os Hupd'äh alegam que os maiores conhecimentos dos Wòhd'äh quanto às coisas dos brancos são usados por esses com o intuito de lhes enganar e roubar, uma vez que os cálculos para a soma dos valores das mercadorias, os modos de negociação envolvendo dinheiro e, principalmente, o manejo da virtualidade do recurso financeiro contido no cartão bancário ou no cartão de um determinado programa social são conhecimentos muito sofisticados do ponto de vista hup, revestidos por uma aura de hermetismo.

Em face do autoritarismo reputado pelos Hupd'äh aos Wòhd'äh, o que possivelmente seja o mais vil atributo moral do ponto de vista da ética hup: /pay id/ "fala feia", "fala má", é uma expressão corriqueira para se referir à sua inabilidade discursiva, que se desencaminha como distrato, bestialidade verbal, constrangimento da parte dos Hupd'äh. Não raro o tema da fuga se coloca: fuga das comunidades ribeirinhas no tempo de trabalho na terra dos Wòhd'äh e, mais recentemente, também a fuga das instituições estatais (de saúde, educação etc.), que contam com grande presença de indígenas dessas outras etnias.

Retomando M1, a chegada a uma determinada localidade e a saída da Cobra-Canoa são eventos que transformam um coletivo específico em gente (humanos), marcando também sua identidade étnica e territorialidade. A precedência e veracidade da enunciação hup estaria tanto no fato de terem sido timoneiros quanto de terem "saído primeiro".

(Wòhd'äh) e os brancos. O termo Wòhd'äh não carrega em si sentidos depreciativos.

MARQUES, Bruno Ribeiro; RAMOS, Danilo Paiva. Dissoluções necessárias: a perspectiva dos Hupd'äh nas relações do "sistema regional do Alto Rio Negro". Espaço Ameríndio, Porto Alegre, v. 13, n. 2, p. 104-131, jul./dez. 2019. 
Saíram primeiro do Lago-de-Leite, conduzindo a todos rio acima. Após a chegada em Ipanoré, a embarcação vai ao rio Papuri, a lauaretê e, posteriormente, ao igarapé Turi, onde desembarcam os Hupd'äh para povoar a região interfluvial dos rios Papuri, Tiquié e Uaupés. Ainda que outros povos tivessem desembarcado antes da chegada ao Turi, a saída dos timoneiros, dos /kih sät/, é tida como a "verdadeira saída" por ser a saída dos guias. Na narrativa M1, para Ricardo, os "seguidores", os Tukano, quando narram as histórias, enunciam percursos e desembarques que não conheceriam com a mesma profundidade que seus "guias", os / kih sät/ dos caminhos. A um só tempo, ao adjetivar as narrativas tukano como "políticas", a liderança hup questiona o caráter absoluto da autoridade dos viajantes Tukano, bem como a fixidez das posições de prestígio hierárquico num campo de relações interétnico, uma vez que a autoridade da fala mítica é um dos componentes desta forma de prestígio. Mas elas não são qualificadas como "verdadeiras" por Ricardo também por descreverem o percurso da viagem da Cobra-Grande de modo diferente. Anteriores aos Tukano, os Hupd'äh e Dâw seriam os conhecedores primordiais do caminho de leite, e em sua "saída". A versão apresentada por Ricardo, ao colocar-se como a versão "verdadeira", parece ser também uma versão "contra-política" - portanto, política ao seu modo -, relativizando a autoridade unívoca tukano de narrar e, subsequentemente, contra uma espécie de totalização que pode derivar de leituras antropológicas das versões tukano.

Logo, a narrativa em M1, ao colocar-se em contraposição às versões mito-políticas de outros povos da região, inspira também questionamentos ao modo como a literatura científica da região consolidou a visão acerca dos povos da família linguística Naduhup. Se, por um lado, a bibliografia é relativamente controversa a respeito das relações entre os povos Tukano e Arawak (seu processo de "aculturação" mútua na formação do sistema regional), por outro, há um tom consensual em relaçãa à posição de dominação cultural na qual se encontram os designados Maku. Como argumenta Wright (1992), o problema fundamental dos estudos é precisamente "o processo de integração histórica do qual surgiu a configuração sociocultural predominante na região" (Wright 1992: 257), configuraçãa essa sintetizada justamente a partir de elementos arawak e tukano. Ainda nesta linha que desdobra as implicações das camadas de ocupação humana da região [Maku > Tukano/Arawak > brancos], Geraldo Andrello identifica um conjunto de questões suplementares às considerações de ordem histórica na formação do sistema regional do alto rio Negro: "[e]m que medida a colonização pesou na moldagem do mosaico de identidades que caracteriza hoje o sistema social nativo da região é, assim, um tema que vem atraindo a atenção de antropólogos e arqueólogos [...]" (2006: 71).

Stephen Hugh-Jones $(1993,1995)$ sugere que os traços hierárquicos do sistema regional e os mitos de origem tukano seriam reminiscências de um "passado grandioso", que remonta às evidencias arqueológicas de sistemas complexos encontradas em outras partes da América do Sul, 
fazendo referência aos trabalhos da arqueóloga Ana Roosevelt (S. HughJones 1993: 116; 1995: 252). Num sentido semelhante, os trabalhos de Vidal (2000), Hill (1989, 1993, 2011) salientam a importância das chamadas "rotas sagradas" arawak abertas por demiurgos, cujas ações narradas nos mitos sobre o Jurupari foram fundamentais para 0 estabelecimento de redes comerciais, rebeliões indígenas e da circulação a lugares sagrados (Vidal, 2000, p. 635). No séc. XIX, muitos grupos Tukano e Arawak participaram de diferentes movimentos milenaristas e utilizaram estrategicamente as "rotas sagradas" arawak para protegeremse face à exploração da empresa da borracha (Hill, 2011 ; Vidal, 2000). As rotas sagradas, conhecidas e utilizadas por muitos xamãs que lideravam as confederações multiétnicas, ligavam sistemas de troca locais e lugares sagrados a regiões exteriores e centros de comércio colonial, e integravam de modo sistêmico diferentes etnias da região (Vidal, 2000, p. 649).

Eduardo Neves (2001), por sua vez, aponta para uma diferença qualitativa fundamental entre o passado e o presente do sistema regional rionegrino. Combinando pesquisa arqueológica, tradição oral dos povos indígenas e evidencias linguísticas, Neves afirma que o sistema regional do alto rio Negro tem origem pré-colonial (2001: 277). Nesta época, segundo Neves, os padrões de organização social encontrados nos dias de hoje já estariam presentes, embora a guerra dos Tukano com os Baniwa do Içana e o rapto de mulheres seriam práticas comuns. $O$ princípio de exogamia não seria tão visível, dada a tendência das relações de aliança concentrarem-se localmente. O mesmo padrão de distribuição hierárquica ao longo dos rios estaria em vigor e as áreas interfluviais seriam ocupadas por povos da família linguística Naduhup, que se relacionavam com os Tukano nos mesmos padrões de "patronagem" observados mais recentemente. Alguns sibs tukano de baixa hierarquia seriam o resultado de incorporações de grupos de caçadores-coletores ("Maku") por parte dos Tukano (Neves 2001: 281). Esta hipótese da assimilação de contingentes "Maku" em sibs de baixa hierarquia tukano e arawak está presente também em Nimuendaju ${ }^{7}$ (1927), acrescentando que mesmo os "Maku" não assimilados sofreram grande influência das culturas arawak e tukano, "ao ponto de certos bandos deste [os Maku] não se distinguirem mais dos seus mestres senão pela língua e pela sua inferioridade social" (Nimuendaju 1927: 165).

De certo modo, em M1, a intenção do narrador em fazer uma contraposição mitopolítica a versões tukano provoca-nos a pensar alguns efeitos potencialmente reificantes das redes de relações rionegrinas em modelos históricos e antropológicos elaborados nos trabalhos relativos ao noroeste amazônico. No sentido de dar inteligibilidade histórica à

\footnotetext{
${ }^{7}$ Segundo Nimuendaju, deste contato entre os antepassados dos Maku com os Arawak e Tukano, a segunda camada formada por "estas tribus superiores", originam-se algumas assimilações que produziram clãs como, por exemplo, os Hohodene dos Baniwa, os quais teriam origem Maku. Robin Wright (1992) tece algumas críticas a esta hipótese de Nimuendaju, afirmando, com base na tradição oral dos Hohodene, assim como em dados lingüísticos, que eles seriam um dos povos Arawak mais antigos na região, o que, segundo Wright, contraria a hipótese de Nimuendaju.
} 
formação deste sistema regional de relativa homogeneidade, alguns autores debruçaram-se sobre o processo de contato entre esses conjuntos humanos de origem heterogenea. Assim, Koch-Grünberg (1909) trata a respeito do processo de "tukanização dos Arawak". Kurt Nimuendaju (1927) propõe a hipótese das "três camadas de civilização", na qual os "Maku" seriam os autóctones propriamente ditos, seguidos pela "segunda camada" que chegou à região em duas levas migratórias, a primeira dos Arawak, a segunda dos Tukano. A "terceira camada" seria um produto híbrido entre a segunda, em particular os Baré, de origem Arawak, e a civilização européia. Wright (1992), criticando os dois autores anteriores, corrobora a aceitação da ordem de ocupação [Maku > Arawak/Tukano > brancos], mas questiona o processo de "tukanização dos Arawak" proposto por Koch-Grunberg, trazendo aspectos que sugerem a ordem inversa de aculturação, e alguns pontos da hipótese de Nimuendaju, dentre os quais, com maior ênfase, o que toca a origem e a data das migrações dos grupos Arawak no noroeste Amazônico.

A hipótese sobre os "primeiros habitantes" da região é formulada inicialmente por Coudreau (1887). O viajante via nos ancestrais dos "Maku" populações primitivas com tecnologia rudimentar que teriam inicialmente ocupado a região. Grupos que possuíam tecnologias mais avançadas teriam, posteriormente, invadido a área e escravizado os "Maku". Stradelli (2009 [1890]), que se refere aos "Maku" como "a raça escrava" e "os antigos senhores da terra", também é evocado por KochGrünberg para sua composição da imagem dos "primeiros habitantes". Koch-Grünberg chega a propor uma espécie de "teoria da dominação", que encontra nas oposições entre agricultores versus caçadores-coletores e sedentários versus nômades as bases para a interpretação das relações entre esses diferentes povos como relações de "senhor e escravo". Tal teoria encontra eco nas formulações de Nimuendajú para quem as toponímias e as urnas funerárias Arawak seriam dados que comprovariam a "primeira onda migratória", que fez com que grupos Arawak, vindos do norte, ocupassem a região, impondo-se sobre os Maku preexistentes (Nimuendajú, 1982, p. 169). Métraux (1963), em The Hunting and Gathering Tribes of the Rio Negro Basin, partindo dos trabalhos de KochGrünberg e Tastevin, reformula de modo interessante a hipótese sobre os "primeiros habitantes". Os grupos Maku atuais seriam os sobreviventes (surviving) das populações que ocuparam primeiramente a Bacia Amazônica, tendo sido em seguida exterminados e assimilados pelos Carib, Arawak e Tukano. Esses povos de cultura mais avançada na agricultura os teriam escravizado ou reduzido à servidão.

Como exposto em Marques (2009, 2015), existem, portanto, entre esses dois conjuntos, "Maku", por um lado, e Tukano e Arawak, por outro, fortes assimetrias no peso da contribuição para a formação do sistema regional do alto rio Negro. Em suma, na literatura científica, Tukano e Arawak aculturam-se mutuamente, sintetizando os traços da "área cultural", e ambos aculturam os "Maku", que, por sua vez, não aculturam ninguém; ao passo que os brancos (colonizadores) aculturam a todos, ainda que em diferentes intensidades, uma vez que, parafraseando uma 
expressão de Jorge Pozzobon (2011), os Hupd'äh seriam os "campeões da resistência". Jorge Pozzobon (1983), ao tratar a respeito do modo como os povos da família linguística Naduhup se inserem no sistema regional do alto rio Negro, ressalta as diferenças entre eles e os outros povos, diferenças essas que Ihes delegam a imagem de "antiexemplo de civilização para os outros índios da área" (Pozzobon 1983: 25).

Voltando a M1, na busca de desdobrar suas consequências teóricas, pensamos que a "política" à qual se refere Ricardo diga respeito à legitimação de territórios e status por meio de narrativas míticas, ao que o professor Hupd'äh apresenta variações, uma narrativa em contraste às versões apresentadas pelas lideranças Tukano - nesse sentido, uma contra-narrativa. Essa versão legitima, política e discursivamente, o lugar dos Hupd'äh e Dâw na cidade como cursistas do Magistério Indígena. Por ocasião da conversa em que Ricardo narrou $\mathrm{M} 1$, o próprio secretário municipal de educação era uma liderança do povo Tukano. Num contexto em que pessoas Tukano assumem posições como professores do Magistério, como diretores do movimento indígena, como missionários, profissionais de saúde, indigenistas da FUNAI e antropólogos, M1 apresenta-se como um enunciado que busca colocar princípios míticos alternativos, afirmando a relevância dos Hupd'äh e Dâw por serem eles os "guias", por seu conhecimento dos caminhos ser condição da formação das gentes rionegrinas.

O contraponto oferecido por M1 mostra os Hupd'äh desembarcando na região do igarapé Turi, ponto de onde iniciaram caminhadas por itinerários distintos a partir dos quais cada clã procuraria constituir seu lugar e morada. Tal narrativa, portanto, ao acentuar na figura conceitual do /kih sät/, dos Hupd'äh e Dâw figurando como "guias", inspira um movimento de atrito com a imagem geral dos povos da família linguística Naduhup cunhada nos primórdios da literatura científica regional e, ainda que modulada ao longo do século $X X$, reverberando ainda hoje sob as variações das imagens de contraexemplo de humanidade, dos "povos marginais" e/ou "servos".

\section{Índios do rio versus índios do mato: o grande divisor e seus efeitos}

Através da justaposição entre uma narrativa mítica dos Hupd'äh e os modelos presentes na literatura etnológica regional buscamos traçar efeitos da generalização de algumas versões no embasamento de modelos teóricos elaborados em uma rede plena de variações mitohistóricas. Essas conexões parciais fazem ecoar, num plano científico, formas de diferenciação e de relações políticas entre os coletivos altorionegrinos $^{8}$. Este trabalho está na esteira das etnografias produzidas nas

\footnotetext{
${ }^{8}$ Lançamos mão da figura conceitual das “conexões parciais" (Strathern 1991) neste texto no sentido de projetar o desafio de não pressupor uma totalização possível na constituição de modelos etnológicos. Aqui nos deparamos com uma discussão intrincada entre a formação do sistema regional do alto rio Negro, a produção de modelos antropológicos, uma certa mereologia neles pressuposta e, o que mais nos interessa neste ensaio, os efeitos etnográficos. A adjetivação "parcial" das conexões aqui em vista não carrega em MARQUES, Bruno Ribeiro; RAMOS, Danilo Paiva. Dissoluções necessárias: a perspectiva dos Hupd'äh nas relações do "sistema regional do Alto Rio Negro". Espaço Ameríndio, Porto Alegre, v. 13, n. 2, p. 104-131, jul./dez. 2019.
} 
Espaço Ameríndio

décadas anteriores com os Hupd'äh e os Yuhupdeh, as quais contrapunham-se conscientemente ao que Howard Reid (1979) chamou de "viés tukano" (bias tukano) marcante da literatura etnológica da região, qual seja, o diagnóstico do "enviesamento" das etnografias que incorporam o ponto de vista dos "índios do rio" sobre "os índios do mato", definindo os segundos de maneira negativa conforme parâmetros a eles exógenos ${ }^{9}$. Jorge Pozzobon (2011) segue este diagnóstico, traçando um processo que qualifica como de "mestiçagem de conceitos e negação da diferença", em que

os primeiros etnógrafos da área assumiram ao menos em parte o ponto de vista dos comerciantes sobre a escravidão e em parte o ponto de vista dos índios do rio sobre a inferioridade dos Maku. Terminaram produzindo etnografias bastante enviesadas. Os Maku foram por eles descritos como um povo arcaico reduzido à escravidão por índios invasores mais desenvolvidos. Ou como povos regressivos, que perderam características culturais mais complexas por causa do escravismo. (Pozzobon 2011, p. 97)

Interessante notar que o diagnóstico desse problema como "viés tukano" e as propostas de solução nos trabalhos antropológicos que se seguiram (Reid 1979; Pozzobon 1982, 1991 e 2011; Athias 1995) parecem presos a uma dinâmica que, ao fim e ao cabo, faz-nos voltar ao ponto inicial da discussão, tendo, portanto, um caráter recursivo. Isto é, temos a sensação que as tentativas que se sucedem de superar o "viés tukano" acabam por colocá-lo de outra forma, em outro lugar. Diante

subtexto nenhum tipo de acusação, como se a essas conexões faltasse algo, como se nelas constasse uma lacuna que, uma vez preenchida, pudesse lhes estipular a posição de "totais". Nosso objetivo, isso sim, é delinear alguns efeitos etnográficos destes modelos no que toca às imagens projetadas aos povos da família linguística Naduhup e, com isso, esperamos, favorecer condições conceituais para descrições vindouras colocadas já em outro plano. Como Marcio Goldman e Eduardo Viveiros de Castro (2017) nos mostram, nos trabalhos de Strathern está colocado um modo transformacional da descrição antropológica, um modo em que sociedades e pessoas seriam transformações recíprocas umas das outras, não se tratando, portanto, de relações de "inversão" ou de "projeção"; rede transformacional essa em que as descrições nativas são elas próprias versões.

\footnotetext{
${ }^{9}$ A realização das primeiras etnografias com povos da família linguística Naduhup (Silverwood-Cope 1990 [1972]; Reid 1979; Pozzobon 1982, 1991, 2011; Athias 1995) permitiu a complexificação das visões possíveis do Noroeste Amazônico. Assim, por exemplo, a ocupação dos interflúvios, a mobilidade espacial, a ênfase na caça e a baixa produtividade agrícola são descritas como escolhas de um modo de vida por parte destes povos, e não como imposições alheias ou como uma questão de desconhecimento, considerando que, se os Hupd'äh plantam para os Tukano, eles sabem plantar, e, da mesma forma, se eles constroem malocas para os Tukano, eles poderiam ter as suas próprias (Reid 1979; Pozzobon 1983; Politis 2001). O tema das relações entre Tukano e Hupd'äh, a partir de então, teve o "bias tukano" (Reid 1979) atenuado. Conforme os etnógrafos, em muitos aspectos a relação dos Hupd'äh com os Tukano seria bastante vantajosa para os primeiros, inclusive porque é justamente a relação com os Tukano que possibilitava o modo de vida de mobilidade espacial dos Hupd'äh, uma vez que os índios ribeirinhos absorveram o impacto da influência dos brancos, funcionando como um meio para os Hupd'äh obterem os objetos industrializados sem a necessidade do contato direto e da missionarização, permanecendo em relativo isolamento geográfico (Ramos et alii 1980: 139-40; Pozzobon 1991). Em suma, o que de determinada perspectiva é imposição, de outra é escolha. 
dessa notável persistência do problema do "viés tukano" da bibliografia, que, como veremos a seguir, atinge em cheio os próprios trabalhos antropológicos realizados com os Hupd'äh, cremos estar diante de um problema etnológico nada simples. Sob o risco de soarmos extravagantes, mas na busca de caminhos conceituais para iluminar, revelar as condições conceituais e mecanismos deste persistente problema, sugerimos aqui que a cisão antropológica entre "índios do mato" e "índios do rio" tomou, em muitos aspectos, a forma de um "grande divisor" na literatura etnológica do noroeste amazônico, o qual tem seus efeitos mais drásticos e contraproducentes nas descrições antropológicas dos povos da família linguística Naduhup pelas razões abaixo expostas.

Destacamos assim uma evidência aparentemente banal: a relação entre Hupd'äh e Tukano passou à literatura etnológica como uma variação da oposição entre sociedades simples e sociedades complexas. Isso ocorre de forma particularmente visível nas considerações de ordem arqueológica e histórica, que partem da ocupação de diferentes nichos ecológicos pelos diferentes povos, a beira dos rios versus o interior das florestas, e vão gradativamente reconstruindo cenários possíveis da formação do sistema regional do alto rio Negro, relegando, neste movimento, os Hupd'äh à posição de fundo paisagístico a partir do qual as figuras históricas propriamente ditas (Tukano, Arawak, não indígenas) vão se destacando. Como dito anteriormente, os traços que definem a homogeneidade cultural do sistema regional $e$ as engrenagens sociopolíticas que articulam a rede entre os coletivos seriam de competência dos Wòhd'äh (Tukano e Arawak); sistema esse que, por sua vez, foi moldado pela e adaptou-se para a situação de contato com os colonizadores.

$\mathrm{Na}$ constituição do noroeste amazônico, de fundo às teorias, debates, hipóteses sobre a profundidade temporal e a distribuição espacial dos povos que constituíram seu passado e com os quais os povos do presente entretêm relações de continuidade, duas imagens socioecológicas fortes operaram, entre as quais uma série de assimetrias medeiam a relação. Como argumenta Eduardo Neves (1998) em sua tese de doutorado, a região é marcada pela congruência entre os marcadores das fronteiras multiétnicas e das fronteiras propriamente físicas referindo-se à distribuição das famílias linguísticas Tukano oriental e Arawak conforme o Uaupés e demais tributários do rio Negro. Além dessa, outra divisão fundamental se baseia na ocupação de diferentes nichos ecológicos, grosso modo, dois ambientes distintos: áreas ribeirinhas versus interflúvios (Neves 1998, p. 113-114), sendo as primeiras ocupadas por povos Arawak e Tukano orientais, ao passo que nas últimas estariam "os caçadores nômades falantes de línguas relacionadas mas não classificadas, frouxamente chamadas de Maku" (Neves 1998, p. 114). De modo distinto da diferenciação de coletivos e das formas como cada clã realiza sua ocupação, a literatura parece opor dois blocos pela ocupação geográfica e formas de habitação. As sutilezas e a complexidade dos processos de diferenciação de coletivos clânicos, os 
diferentes modos de habitação e as formas de reciprocidade e vida ritual dos grupos hup acabam cristalizando-se nas imagens do "povo caçador", dos "índios do mato" ou da "sociedade de fluidez" que vão adjetivando os modos de socialidade hup e guiando o olhar dos analistas para a desconsideração de princípios alternativos, como as relações assimétricas internas ("hierarquia") e formas de habitação mais permanente (malocas).

Consolidou-se assim a divisão que passou à literatura etnológica do Noroeste Amazônico como a distinção entre os "índios do rio" - famílias linguísticas Tukano oriental e Arawak - e os "índios do mato" - família linguística Naduhup. Grosso modo, os primeiros seriam sedentários e teriam agricultura mais desenvolvida, enquanto os outros, por sua vez, se caracterizariam por uma mobilidade relativamente intensa por terra, desenvolvendo uma sofisticação maior das técnicas de caça; de um lado, horticultores sedentários estabelecidos nas beiras dos rios estruturados hierarquicamente; de outro, caçadores-coletores noimades habitantes das regiões interfluviais, caracterizados por uma organização social fortemente igualitária (Politis 2001, p. 26).Em "Como se faz um grande divisor?", Goldman e Lima (1999) apresentam a tendência do pensamento antropológico em opor "nós" e "eles", batizada por Jack Goody como Great Divide, traduzida pelos autores como "grande divisor" ou "partilha", tendo como pano de fundo justamente a sensação de uma "espécie de fosso" entre a antropologia realizada com sociedades indígenas e a antropologia realizada com as sociedades complexas (1999, p. 83). Os grandes divisores, entretanto, não necessariamente se dariam entre grandes conjuntos abstratos, como "nós" e "eles", podendo ocorrer também "com objetos relativamente menores como oral e escrita, ou ainda mais específicos, como as noções de tempo linear e tempo cíclico" (1999, p. 84). O grande divisor seria, em suma, um mecanismo relativamente simples de "produção de assimetrias que realiza uma série de operações" (1999, p. 85). Dentre as seis operações destacadas pelos autores (1. identificação, 2. sinédoque, 3. desproporção, 4. projeção, 5. juízo de relação como atributo do objeto e 6 . sobrecodificação), concentramo-nos nas que tocam mais diretamente aspectos do problema que tencionamos trazer à superfície, ainda que, vale a ressalva, a trama dos mecanismos pelos quais as operações se engendram é sobremaneira intrincada, não sendo possível, portanto, o isolamento de operações.

A primeira operação é uma "identificação primeira" que articula a base de comparação, os termos da comensurabilidade, e cuja condição de possibilidade localiza-se na concepção prévia dos elementos a identificar como "unidades", revelando assim uma segunda dimensão do problema do grande divisor, na medida em que "não se encontra apenas nas assimetrias que produzem, mas na concepção substancialista daquilo que se separa" (1999, p. 85). Esta identificação primeira, portanto, substancializa as unidades em comparação [Hupd'äh : Tukano :: Índios do Mato: Índios do Rio] e institui uma assimetria fundante entre elas, desdobrando desta dupla inscrição um efeito que gostaríamos de pôr em relevo, uma vez que, no modelo sociológico do sistema regional rionegrino, toda a heterogeneirade e densidade dos Hupd'äh, de modo 
específico, e dos povos Naduhup, de modo abrangente, são eliminadas "em benefício de uma concepção unidimensional da diferença" (Goldman \& Lima 1999, p. 85). O olhar analítico rionegrino enviesado toma, de modo substancialista, uma das unidades de comparação (Tukano ou Arawak) como sendo o ponto de referência para a definição tanto de si própria (em seus próprios termos) como da outra unidade ("Maku" índios do mato), igualmente substancializada, mas a qual sofreria um processo assimétrico de "empobrecimento ou laminação" (idem).

Como visto, segundo a literatura etnológica da região, os povos Tukano e Hupd'äh estabelecem relações históricas complexas em um sistema regional cuja estrutura é articulada, basicamente, pela regra de exogamia linguíistica - do qual os povos Naduhup não participariam, sendo linguisticamente endogâmicos - e por um sistema de trocas - no qual os Hupd'äh destacam-se por sua especialidade na caça e na coleta de produtos silvestres, bem como, tradicionalmente, no artesanato de cestos (aturá). Não obstante a origem variada das populações, a região destaca-se por uma notável homogeneidade dos traços culturais e de organização social, o que é comumente referido como a "área cultural do alto rio Negro" (Galvão 1959, p. 16).

Essa notável homogeneidade seria mais acentuada, vale ressaltar, entre os povos Tukano e Arawak (Pozzobon 1983). A distinção entre "índios do rio" e "índios do mato" toma outro relevo em vista disto, uma vez que a relativa homogeneidade dos Tukano e Arawak, se comparados aos Naduhup, desdobra-se em uma relativa hegemonia desde a perspectiva do sistema regional, uma considerando que os traços definidores do sistema rionegrino são, via de regra, imputados às populações indígenas ribeirinhas, ao passo que os Hupd'äh, na bibliografia, aparecem como figuras que se adaptam a este sistema do qual não participam plenamente e no qual ocupam posição subalterna aos demais povos, entretendo com eles relações que já foram descritas como escravidão, patronagem, simbiose etc. (Ramos et alii 1980).

Como sugerem Goldman e Stolze Lima (1999), a sinédoque trata da operação pela qual, assim como na figura de linguagem que lhe dá nome, toma-se a parte pelo todo, representando, desta forma, o todo de um dado conjunto, de uma das unidades de comparação, por alguns de seus elementos "escolhidos entre aqueles que se opõem de maneira mais aguda aos elementos escolhidos para representar o outro conjunto [o conjunto de referência]" (1999, p. 86). Como mostramos, uma das ferramentas descritivas generalizadas nos estudos dos Hupd'äh é justamente a comparação com os dados etnográficos sobre os "índios do rio", em particular, os dados sobre os povos da família linguística Tukano, de modo que um frequentemente constitui-se como a imagem diametralmente invertida do outro, operando uma série de contraposições, como por exemplo: cognatismo e ambilocalidade dos arranjos locais hup versus unilocalismo agnático tukano; mobilidade espacial versus sedentarismo; endogamia linguî́stica versus exogamia linguî́stica; moradia em tapiris versus moradia em malocas. A sinédoque marca o movimento através do qual estes termos em comparação são 
isolados de seus contextos concretos e, tomados em seu potencial contrastivo e mutuamente excludente, passam a definir cada uma das unidades enquanto totalidades. Doravante, portanto, o que define os Tukano, por definição, não definirá os Hupd'äh.

O grande efeito disto que estamos tomando como um grande divisor nas teorias etnográficas sobre os Hupd'äh é uma tendência ao que podemos chamar de excepcionalismo Maku: procedimento pelo qual o que lhes é singular tem de necessariamente excluir semelhanças com os Tukano. Nesta lógica, o que define os Hupd'äh enquanto tal não poderia ser um traço atribuível aos Tukano. Daí a necessidade de Pozzobon negar o "agnatismo-hierárquico", relegando-o ao plano imaginário, instituindo uma diferença radical, que seria o "cognatismo-minimalista", opondo duas naturezas societárias, as "sociedades da regra" e as "sociedades do improviso" (Marques 2009, 2011 ). Enquanto isso, Reid (1979) tenderia à solução de gradiente: os rituais, os mitos, o xamanismo dos Hupd'äh seriam "empobrecidos" em relação aos Tukano. Duas formas de reificação dos Hupd'äh, duas variações do grande divisor: reificação de natureza e reificação de gradiente, respectivamente. Pensamos que o principal problema destas abordagens é que, com elas, a antropologia nega os meios pelos quais os próprios Hupd'äh constituem seus coletivos e pessoas, isto é, os meios pelos quais eles próprios se definem e se diferenciam das alteridades em jogo.

Isso nos encaminha para a próxima operação: "juízo de valor como atributo do objeto", caracterizada pelo que os autores diagnosticaram como um "colapso entre metodologia e ontologia". A possibilidade heurística do método comparativo em revelar atributos de determinado sistema - por exemplo, a hierarquia de castas na Índia - ao contrastar com outro - as ideologias da igualdade e do individualismo - não pode implicar, no entanto, a substanciação dos juízos dele derivados. 0 problema se coloca, assim, quando se eclipsa o caráter relacional e metodológico dos juízos advindos da comparação, tomando-os como atributos intrínsecos ao objeto. É precisamente nesta operação que vimos verter os "juízos de fluidez" atribuídos aos Hupd'äh (descritos em detalhe

\footnotetext{
${ }^{10}$ No discurso científico, o tema da diferença surge a partir do contraste entre dois conjuntos de povos (índios do rio e índios do mato) replicando-se, desta forma, no plano da relação entre ideal e prática nativos, uma vez que a relativa coerência entre o discurso e a prática tukano opõe-se à notável inconstância dos Hupd'äh em suas relações com as regras em geral. Isso implica as imagens de "fluidas", "flexíveis", "ambíguas", "desviantes" no que toca à observância das regras. Já na monografia de Peter SilverwoodCope foi apresentada a distinção entre um modelo ideal de sociedade, através do qual os Kakwa descrevem "seu sistema de parentesco, regras de casamento e sistema de clãs" - modelo esse compartilhado com os demais povos da região - , e o comportamento real, que diz respeito a "agrupamentos significativos, grupos locais e regionais que frequentemente cruzam a organização social", correspondendo a um modelo diferente do ideal (Silverwood-Cope 1990 [1972], p. 77). Howard Reid (1979), em seu trabalho sobre os Hupd'äh, é o primeiro autor a usar abertamente a linguagem da "fluidez" e da "ambigüidade", sem, entretanto, avançar teoricamente a respeito, embora deduza, a partir do discurso nativo, algumas regras operantes em seu sistema de parentesco que não estão previstas no modelo da patrilinearidade exogâmica. Já, Jorge Pozzobon, em sua tese de doutorado (1991), baseado em uma hipótese demográfico-estrutural, como ele próprio nomeia, atribui a causa da desobediência à regra de exogamia a desequilíbrios demográficos: os Hupd'äh e Yuhupdeh, não tendo um isolado matrimonial suficientemente numeroso, simplesmente não poderiam praticar suas regras de casamento com precisão.
} 
em Marques 2009), o que, na comparação com os Tukano, coloca uma cisão entre a amorfia da sociedade de uns e a complexidade da sociedade dos outros, proliferando as descrições antropológicas dos Hupd'äh com os signos da falta (de mitos próprios, regras eficazes, rituais elaborados, territórios de referência).

Goldman \& Lima (1999) apresentam uma última operação para a constituição dos grandes divisores, a "Sobrecodificação", que subordina ou comanda as outras anteriores, articulando "os feixes de oposições, batizando-os com os grandes significantes que esmagam a diversidade efetiva que corta por dentro e por fora os grupos humanos" (1999, p.89). Trata-se justamente da sobrecodificação das diferenças, baseada na premissa de uma diferença genérica e invariável - a "simples contraface da identidade" -, e não de "modalidades de diferença que diferem entre si" (1999, p.85). Isto é, a sobrecodificação transforma a diferença cultural em oposição, de modo a negar que as "modalidades de relação sejam contextuais, variando no interior de uma mesma sociedade e - por que não? - nas experiências de um mesmo sujeito" (1999, p.86). A laminação, portanto, da diversidade efetiva.

\section{Movimentos e posições}

Retomando, uma vez mais, M1, segundo Reid (1979, p.199-200), é justamente a inversão mítica das relações assimétricas entre irmão mais velho e irmão mais novo - segundo a ordem de emergência das gentes no ciclo mítico da Cobra-Canoa - que possibilita as diferentes perspectivas do sistema. Para o autor, a assimetria do sistema, para os Tukano, é vista de forma mais fixa, enquanto os Hupd'äh tenderiam a enfatizar as "ambiguidades" do mito, articulando a não-fixidez da hierarquia, como no caso da narrativa de Ricardo e o princípio do /kih sät/ ("guia", "o que chama a ação"). Com a análise da versão mítica sobre a Viagem na Cobra-Canoa (M1), é possível perceber como as inversões realizam-se a partir de um conjunto mais amplo de princípios de diferenciação orientados pela mobilidade e pelas posições ocupadas num campo de relações que se estabelecem ao longo dos percursos. Neste sentido, além dos efeitos teóricos que M1 provoca na etnologia regional, é interessante apresentar brevemente outros dados para a complexificação da perspectiva dos Hupd'äh nas relações do sistema regional do alto rio Negro, contrapondo-se aos efeitos do grande divisor acima delineados. Para tanto, buscaremos traçar como princípios e contrastes definidores do sistema regional são replicados em um coletivo regional hup, dando forma às suas relações e diferenças internas, e em suas relações com os demais grupos regionais.

Os Hupd'äh do igarapé Japu e os Hupd'äh de Santa Cruz do Cabari (comunidade no igarapé Cabari, no limite sul do grupo regional) tomam suas variantes dialetais, suas /id/, "falas/línguas" como marcos diacríticos de diferenciação. Em Santa Cruz fala-se uma mistura da /id/ (variante dialetal) do igarapé Japu com a /id/ do rio Tiquié. Esta comunidade no limite sul do grupo regional oriental é um ponto de passagem espacial e 
sociológico para outro grupo regional hup, da "gente do Tiquié", casando, em grande medida, com os Hupd'äh de Taracuá Igarapé, afluente do rio Tiquié. Em relação aos Hupd'äh do alto Papuri, o ponto de passagem é a /id/ (variante dialetal) no igarapé Turi. Além da "fala", as diferenças entre os Hupd'äh do alto Papuri e os Hupd'äh do Japu são marcadas por distinções civilizacionais, uma vez que, conforme os Hupd'äh do Japu, os do alto Papuri não seriam batizados nem teriam escolas, não saberiam ler e escrever. Também não conheceriam o preparo do arroz, do feijão e da carne de frango, não têm documentos, nem conhecem o dinheiro, além de ter vergonha de falar a língua Hup na presença dos Tukano.

Tal relação, que toma os signos da civilização diferencialmente distribuídos conforme o curso do rio Papuri (de oeste a leste, do alto ao baixo curso, opondo grupos regionais hup), tendo os Hupd'äh do alto Papuri em um extremo e os Wòhd'äh que formaram a cidade de lauaretê, na foz do Papuri, em outro, replica-se no interior do próprio grupo regional oriental dos Hupd'äh. Coloca-se, assim, uma distinção entre Fátima (os Hupd'äh da cidade indígena de lauaretê) e os Hup'äh das comunidades do Japu, sendo o caminho entre essas localidades feito por uma trilha na qual, assim como no fluxo dos rios, se "desce", /hí/, para Fátima e se sobe, /pé/, para o Japu. Os Hupd'äh de Fátima, comunidade hup em lauaretê, afirmam sua proximidade das mercadorias e hábitos dos brancos em oposição aos parentes que vivem nas comunidades no interior da floresta, os quais teriam uma vida penosa pela dificuldade de acesso aos bens de origem não indígena. Por seu turno, os Hupd'äh das comunidades do Japu dizem que os Hupd'äh de Fátima também, ao seu modo, têm uma vida penosa, pois passam fome, dependem exclusivamente da alimentação dos brancos, do trabalho com os Wòhd'äh de lauaretê e do dinheiro para sobreviver, não respeitando as restrições rituais e resguardos alimentares. O tema e a controvérsia em relação à boa distância da cidade, e tudo que a cidade implica, é uma tônica da vida dos Hupd'äh contemporâneos, que realizam uma série de experimentos no sentido de equacionar o melhor dos dois mundos, digamos assim, das duas abundâncias, a da floresta e a da cidade e suas mercadorias.

A realização das primeiras pesquisas baseadas em trabalho de campo intensivo com os Hupd'a'h (Reid 1979; Pozzobon 1983, 1991; Athias 1995), seguidas de uma segunda leva mais recente (Ramos 2014; Marques 2015), revelou a complexidade da estrutura social dos Hupd'àh, organizados em um conjunto de mais de vinte clãs em concentrações regionais, divididos em duas metades. Entre os diferentes clãs há, portanto, duas relações possíveis: /bab'/ (consanguíneos) e yoh (cunhados). Da mesma forma que os grupos de descendencia dos demais povos da região, cada um desses clãs divide-se em linhagens hierarquicamente estruturadas, cujas relações são designadas a partir da terminologia de parentesco entre irmãos: /sät/ (irmão maior), /yowàm/ (irmão menor). Tudo se passa, portanto, como se os Hupd'ảh dobrassem para seu interior (linguisticamente endogâmico) as relações de exogamia do sistema regional do alto rio Negro. Além do mais, é relevante notar a importância simbólica dos clãs na vida dos Hupd'àh. Cada um desses 
coletivos é formado por cantos, repertórios míticos, objetos rituais (flautas jurupari) e por substâncias físicas e xamânicas próprias que os conectam aos /Hib'ah Tẽhd'äh/ (Filhos do Nascimento), os primeiros ancestrais a chegarem nesta terra através de /Hib'ah M'eh/ (Cobra do Nascimento).

Atualmente há três clãs mais expressivos na região do Japu, os /Mòy Kä' Tẽ̉hd'äh/ (“Filhos do Osso do Veado"), os /Dëh Puh Tẽ̃h d'äh/ ("Filhos da Espuma d'Água") e os /Dög M'èh Tềh d'äh/ ("Filhos da Cobra Uirapixuna"). Esses clãs têm maior contingente populacional e a relação com as terras do Japu remete a um vínculo de origem. Entre eles se articula a trama exogâmica e de parentesco basal do igarapé Japu contemporâneo: os /Mòy Kä' Tẽ̀h d'äh/ casam com os /Dëh Puh Tẽh d'äh/ e com os /Dög M'èh Tẽ̀h d'äh/, e esses últimos não casam entre si, definindo duas relações entre os clãs, /yòh/ ("cunhados") e /báb'/ (parentes). Importante destacar que essa relação entre os clãs apresentada implica, do ponto de vista dos Hupd'äh, exogamia linguística em certo sentido, na medida em que há algum tempo cada um desses clãs falava uma /id/ (língua) própria. Atualmente, entretanto, todos valem-se apenas da /id/ dos /Mòy Kä' Tềh d'äh/, sendo, segundo os Hupd'äh, essa generalização da "fala" de um dos clãs um fenômeno relativamente recente.

Na sequência das relações de analogia, os Hupd'äh explicam que teria ocorrido com os /Dëh Puh Tềh d'äh/, os /Dög M'èh Tẽ̀h d'äh/ e demais clãs da região o mesmo que se passou com os Tariano e outros indígenas que perderam a sua língua própria e hoje falam apenas a língua Tukano"1. Em Santa Cruz do Cabari, concentram-se os irmãos menores (agnatos de status inferior) desses três clãs do igarapé Japu, cuja conexão genealógica não é possível estabelecer com os irmãos maiores (dispersos nas demais comunidades), formando uma espécie de nebulosa de baixa hierarquia hup e imprimindo, neste grupo regional, um traço de divisão espacial com base em distinções hierárquicas.

clã hup $\mathrm{A}$ : clã hup $\mathrm{B}$ :: etnia woh $\mathrm{C}$ : etnia woh $\mathrm{D}$ :: nação $\mathrm{E}$ : nação $\mathrm{F}$

$$
\begin{gathered}
\text { Hupd'äh } \rightarrow \text { Moy Kä' Tẽhd'äh : Dëh Puh Tẽhd'äh } \\
:: \\
\text { Wòhd'äh } \rightarrow \text { Tukano : Desano } \\
:: \\
\text { brancos } \rightarrow \text { brasileiros : colombianos }
\end{gathered}
$$

Da perspectiva hup, trata-se da mesma ordem de diferença e

\footnotetext{
11 A expansão da língua Tukano e enfraquecimento de línguas minoritárias na região se daria pela concorrência de duas razões, uma propriamente colonial que remete ao aparato dos internatos salesianos (Cabalzar 2013, p. 131), a outra de ordem sociológica, uma vez que o grupo linguístico Tukano teria sido melhor sucedido em ampliar o leque de alianças, tornando-se um dos principais fornecedores de mulheres aos demais grupos do Uaupés (Andrello 2016), sendo assim a língua Tukano disseminada de mãe para filho entre os demais povos. Se considerarmos a posição dos /Mòy Kä' Tềhd'äh/ na rede exogâmica deste grupo regional dos Hupd'äh, os quais casam tanto com os /Dëh Puh Tềh d'äh/ como com os /Dög M'èh Tềh d'äh/ - que, por sua vez, não casam entre si -, talvez seja uma chave para o entendimento do processo pelo qual a "fala" /mòy kä'/ tomou essa abrangência geral entre os Hupd'äh da região do Japu. 
relação que se replica nas séries acima destacadas, alterando-se apenas a quantidade de indivíduos, a qual aumenta exponencialmente na passagem de uma série para outra. Em suma, se tomarmos como referência os traços definidores do sistema regional, tais como a exogamia linguística e o gradiente civilizacional (Baré versus Tukano, baixo curso versus alto curso do rio) nas descrições até o momento apresentadas, deparamo-nos com uma situação em que a trama de diferenciações dos Hupd'äh - a exogamia clânica (linguística em certo sentido), em suas malocas e tapiris, entre civilizados e não-civilizados, irmãos maiores e menores... - replica a complexidade do sistema regional do alto rio Negro. Aproximamo-nos de um aspecto do sistema tal qual descrito por Marilyn Strathern para a Papua Nova Guiné, em que princípios:

[...] radically distinguishing whole clusters of societies are also replicated within them... As a consequence, what distinguishes the Mountain Papuan Baruya from Hagen in the Central Highlands also appears to the observer to distinguish elder and younger Arapesh brothers in the single settlement of Ilahita. (Strathern 1991, p. xviii)

Do ponto de vista do observador, da antropologia, o sistema regional implicaria, portanto, uma espécie de complexidade constante das relações e informações independentemente da escala de análise; isto é, fractais. Ao lançarmos mão destas ideias, importante explicitar que a intenção última é justamente borrar a ideia de escala em nosso objeto de análise, a qual, pensamos, ainda que tenha validade como recurso heurístico para a antropologia, não seria, no entanto, uma boa imagem para traduzir a perspectiva dos Hupd'äh, pois tomando as analogias entre as séries de relação exogâmica [Hupd'äh - Wòhd'äh - brancos] que os Hupd'äh nos apresentam, não se poderia estabelecer o ponto de origem da relação, do qual partiriam, por derivação, as replicações nos outros pontos.

O conjunto de relações das quais se abstrai o "sistema regional do alto rio Negro" não seria algo marcado por uma oposição entre dentro e fora, definindo uma hierarquia de englobamento (continente-conteúdo), ou de pertencimento parcial, pressupondo uma totalidade e relações de englobamento. Seria um conjunto de princípios e marcadores que modulam uma multiplicidade de gentes e pessoas em relação de contiguidade espacial, e que, no contexto da cidade, do encontro multiétnico em um mesmo espaço, tende a um rearranjo das relações, como sugerem alguns processos recentes vividos pelos Hupd'äh em lauaretê e, sobretudo, em São Gabriel da Cachoeira'2.

\footnotetext{
${ }^{12}$ Este ensaio deve ser desdobrado em uma segunda parte, onde trabalharemos, a partir da crítica aos efeitos do grande divisor aqui exposta, composições possíveis com trabalhos recentes da etnologia regional que se colocam no mesmo sentido de complexificação dos modelos descritivos, tais como: S. Hugh-Jones (2013a, 2013b), Lolli (2014) e Andrello (2016). 


\section{Considerações finais}

A bem dizer, os parágrafos anteriores não estão livres de eventuais exageros. Uma série de ressalvas, exceções, variações, matizes podem ser colocadas quanto à bibliografia. Mas a apresentação assim um pouco bruta se dá justamente no intuito de destacar o que descrevemos como os efeitos do grande divisor entre os "índios do mato" e os "índios do rio" que operou e continua a operar na bibliografia. Tendo como referência o posicionamento e ponto de vista dos Hupd'äh no campo mitopolítico e interétnico regional, buscamos identificar os fatores que levam os trabalhos sobre povos Tukano, de um lado, e os trabalhos sobre os Hupd'äh, de outro, a comporem modelos e discursos que reforçam grandes divisores em benefício de uma visão unidimensional da diferença. Na literatura científica, é comum que os povos da família linguística Naduhup tomem a imagem de uma espécie de protohumanidade tão estendida quanto onipresente, ocupando todos os espaços em que ninguém mais deseja estar.

Tudo se passa como se sempre estivessem aí, parte da natureza, da paisagem ela própria, moldados - a partir do grau zero da formação do sistema regional do alto rio Negro (objeto de debate) - pela ação humana e pelos traços da "área cultural" duramente forjados pelos embates entre os conjuntos humanos que foram se somando e sucedendo em ondas no território alto-rionegrino. E considerando que, afinal de contas, não se tem exatamente ideia de como eram os Hupd'äh antes da chegada dos Tukano, dos Arawak e dos brancos ${ }^{13}$, eles parecem condenados ad eternum a não serem eles mesmos. Todo o traço cultural lhes seria exógeno e fruto de aculturação, à exceção de alguns itens de ordem material: por exemplo, a zarabatana, as técnicas artesanais para a feitura de cestos, a preparação do curare; itens esses que lhes são tidos como singulares justamente por definirem sua posição como figuras estritamente complementares aos demais da região.

Nos magistérios indígenas e nos acampamentos na cidade de São Gabriel da Cachoeira, inserindo-se cada vez mais em campos de relação em que são discriminados, roubados e excluídos socialmente, contextos esses dominados por pessoas de outras etnias, por não indígenas e por lógicas a eles estranhas, é possível perceber como o tema da Viagem da Cobra-Canoa colabora com a constituição de uma noção de identidade hup. Diacriticamente, o narrador hup sustenta sua autoridade ressaltando sua posição de guias cujo saber e conhecimento dos caminhos coloca-se como uma condição sine qua non para a existência humana dos demais povos, para a existência de seus territórios e para que detenham poder e prestígio.

\footnotetext{
${ }^{13}$ Apenas por inferência a partir de narrativas míticas que os próprios Hupd'äh contam a respeito da sua vida anterior ao roubo dos produtos agrícolas do sogro gente-peixe, sem necessariamente opor este modo de vida aos Tukano e aos Arawak, pois se trata de um mito que apresenta variações em diversos povos do rio Negro, não sendo, portanto, um elemento diacrítico.

MARQUES, Bruno Ribeiro; RAMOS, Danilo Paiva. Dissoluções necessárias: a perspectiva dos Hupd'äh nas relações do "sistema regional do Alto Rio Negro". Espaço Ameríndio, Porto Alegre, v. 13, n. 2, p. 104-131, jul./dez. 2019.
} 
Espaço Ameríndio

A "resistência hup" explicitada pelas narrativas aponta caminhos no sentido da dissolução do "grande divisor" que nega sua posição ativa como sujeitos coletivos articulados de modo complexo e pluridimensional ao "sistema regional rionegrino". Aceitar segui-los exigirá o distanciamento quanto à unidimensionalidade da diferença suposta pelos modelos atuais que apagam heterogeneidades e densidades, consolidando um "juízo de valor como atributo do objeto" que coloca em risco toda a empreitada da síntese sociológica comparativa regional. Interromper a projeção dos "juízos de fluidez" aos povos Naduhup tornase urgente para que seja possível consolidar estudos sobre a mitopolítica rionegrina como uma operação de descolonização do pensamento. 


\section{Referências bibliográficas}

ANDRELLO, G. Cidade do índio: transformações e cotidiano em Iauaretê. São Paulo: Edunesp/ISA/NuTI, 2006.

ANDRELLO, G. Nomes, Posições e (contra) Hierarquia: coletivos em transformação no Alto Rio Negro. Ilha, Florianópolis, v. 18, n. 2, p. 57-97, dez. 2016.

ÅRHEM, K. The Maku, the Makuna and the Guiana system. Ethnos, v. 54, n. 1-2, p. 5 22, 1989.

ATHIAS, R. Hupdë-Maku et Tukano: relations inégales entre deux sociétés du Uaupés, amazonien (Brésil). 1995. 157 f. Tese (Doutorado em Antropologia) UNIVERSITÉ DE PARIS X NANTERRE, Paris, 1995.

ATHIAS, R. Ocupação espacial e territorialidade entre os Hupdah do Rio Negro, Amazona. In: BECERRA, G. (Org). Viviendo en el bosque. Medellín: Ed. Universidad Nacional de Colombia, 2010. p. 57-84.

BECERRA, G.; FRANKY CALVO, C. E.; MAHECHA RUBIO, D. Los Maku del noroeste amazônico. Revista Colombiana de Antropología, Bogotá, v. 33, p. 85-132, 1996/1997.

BOLAÑOS, K. Kakua Phonology: First Approach. 2010. 118 f. Dissertação (Mestrado em Linguística) - University of Texas, Austin, TX, 2010.

CABALZAR, A. Organização socioespacial e predomínios linguísticos no rio Tiqué. In: EPPS, P.; STENZEL, K. (Orgs). Upper Rio Negro: cultural and linguistic interaction in Northwestern Amazonia. Rio de Janeiro: Museu do Índio - FUNAI, Museu Nacional, 2013. p. 129-161.

CAYON, L; CHACON, T. Conocimiento, historia y lugares sagrados. La formación del sistema regional del alto río Negro desde una visón interdisciplinar. Anuário Antropológico, Brasília, UnB, v. 39, n. 2, p. 201-233, 2004.

COUDREAU, H. A. La France equinoxiale. Vol. 2 - Voyage à travers les Guayanes et l'Amazone. Paris, 1887.

EPPS, P. A Grammar of Hup. 2005. 799 f. Tese (Doutorado em Linguística) UNIVERSITY OF VIRGINIA, Virginia. 2005.

EPPS, P. Language and Subsistence patterns in the Amazonian Vaupés. In: GÜLDEMAN, Tom; RHODES, R.; MCCONVELL, P. (Orgs). The Languages of Hunter-Gatherers: Global and Historical Perspectives. Cambridge: Cambridge University Press. (no prelo)

EPPS, P.; BOLANOS, K. Reconsidering the 'Makú' family of northwest Amazonia. MARQUES, Bruno Ribeiro; RAMOS, Danilo Paiva. Dissoluções necessárias: a perspectiva dos Hupd'äh nas relações do "sistema regional do Alto Rio Negro". Espaço Ameríndio, Porto Alegre, v. 13, n. 2, p. 104-131, jul./dez. 2019. 
Espaço Ameríndio

International Journal of American Linguistics, v. 83, n. 3, p. 467-507, 2017.

FOIRN e ISA, Levantamento Socioambiental com as comunidades das TIs do médio e alto Rio Negro, 2017.

GALVÃO, E. Aculturação Indígena no Rio Negro. Boletim do Museu Paraense Emílio Goeldi, Antropologia, v.7, p. 1-64, 1959.

GIACONE, A. Pequena Gramática e Dicionário Português Ubde-Nehern ou Macú. Amazonas, Brazil: Missão Indígena Salesiana, Rio Uaupés/Rio Negro, 1955.

GOLDMAN, M.; LIMA, T. S. Como se faz um grande divisor? In: GOLDMAN, M. Alguma antropologia. Rio de Janeiro: Relume-Dumará, 1999. p. 83-92.

HILL, J. Ritual reproduction of environmental History among the Arawakan Wakuénai of Venezuela. Human Ecology, v. 17, n. 1, p. 1-25, 1989.

HILL, J. Keepers of the sacred chants. Tucson: University of Arizona Press, 1993.

HILL, J. Sacred Landscapes as Environmental Histories in Lowland South America. In. HORNBORG, A.; HILl, J. (Orgs.). Ethnicity in Anciety Amazonia. Boulder: University Press of Colorado, 2011. p. 259-278.

HUGH-JONES, C. From the Milk River. Cambridge: Cambridge University Press, 1979.

HUGH-JONES, S. The Palm and the Pleiades. Cambridge: Cambridge University Press, 1979.

HUGH-JONES, S. Clear descent or ambiguous houses? A re-examination of Tukanoan social organization. In: DESCOLA, P. La Remontée de l'Amazone: anthropologie et histoire de la societés amazoniennes. L’Homme, v.126-128, p. 95-120, 1993.

HUGH-JONES, S. Inside-out and back-to-front: the androgynous house in Northwest Amazonia. In: CARSTEN, J.; HUGH-JONES, S. (Orgs.). About the house: LéviStrauss and beyond. Cambridge: Cambridge Univ. Press, 1995. p. 226-252.

HUGH-JONES, S. Escrever na pedra, escrever no papel. In: ANDRELLO, G. (Org.). Rotas de criação e transformação. São Gabriel da Cachoeira/São Paulo: ISA/FOIRN, 2012. p. 138-167.

HUGH-JONES, S. Bride-service and the absent gift. Journal of the Royal Anthropological Institute, 192, p. 356-377, 2013.

KOCH-GRUNBERG, T. Die Maku. In: RAMOS, D; OBERT, K. "Uma tradução do artigo 'Die Maku' de Theodor Koch-Grünberg (1906)". Revista de Antropologia, v. 6, n. 2, 2017. p. 588-633.

JOURNET, N. La paix des jardins. Structures sociales des Indiens curipaco du haut

MARQUES, Bruno Ribeiro; RAMOS, Danilo Paiva. Dissoluções necessárias: a perspectiva dos Hupd'äh nas relações do "sistema regional do Alto Rio Negro". Espaço Ameríndio, Porto Alegre, v. 13, n. 2, p. 104-131, jul./dez. 2019. 
Espaço Ameríndio

Rio Negro (Colombie). Paris: Institut d'Ethnologie, 1995.

LIMA, T. S. Um peixe olhou para mim: o povo Yudjá e a perspectiva. São Paulo/Rio de Janeiro: ISA/Editora Unesp/NuTI, 2005.

LOLLI, P. Atravessando Pessoas no Noroeste Amazônico. Mana, v. 20, n. 2, p. 281-305, 2014.

LOLLI, P. A plasticidade Maku. Ilha. v. 18, n. 2, p. 177-198, dez. 2016.

MARQUES, B. R. Figuras do Movimento: os Hupda na literatura etnológica do Alto Rio Negro. 2009. 203 f. Dissertação (Mestrado em Antropologia Social) - PPGASMuseu Nacional, UFRJ, Rio de Janeiro, RJ, 2009.

MARQUES, B. R.. Prefácio. In: POZZOBON, Jorge. Sociedade e improviso: estudo sobre a (des)estrutura social dos índios Maku. Rio de Janeiro: Museu do Índio, 2011. p. Xv-Xxxiii.

MARQUES, B. R. Os Hupd'äh e seus mundos possíveis: transformações espaçotemporais do Alto Rio Negro. 2015. $268 \mathrm{f}$. Tese (Doutorado em Antropologia) - PPGASMuseu Nacional, UFRJ, Rio de Janeiro, RJ, 2015.

MÉTRAUX, A. The hunting and gathering tribes of the Rio Negro Basin. In: STEWARD, Ju. Handbook of South American Indians. New York: Ed. Cooper Square Publishers, 1963. p. 861-867.

MÜNZEL, M. Notas preliminaries sôbre os Kabori (Makú entre o Rio Negro e o Japurá). Revista de Antropologia, São Paulo, v.17/20, p. 137-181, 1969/1972.

NEVES, E. Paths in dark waters: archeology as indigenous history in Upper Rio Negro Basin. 1998. Tese (Doutorado em Arqueologia) - INDIANA UNIVERSITY, Bloomington, 1998.

NEVES, E. G. Indigenous Historical Trajectories in the Upper Rio Negro Basin. In: MCEWAN, Colin; BARRETO, Cristiana; NEVES, Eduardo (Orgs.). Unknown Amazon: Nature in Culture in Ancient Brazil. Londres: Inglaterra. 2001. p. 266-285.

NIMUENDAJU, C. Reconhecimento dos rios Içana, Ayarí e Uaupés. Relatório apresentado ao serviço de Proteção aos Índios do Amazonas e Acre. 1927.

POLITIS, G. Nukak ethnoarchaeology of an Amazonian people. Walnut Creek: Left Coast Press, 2007.

POZZOBON, J. Isolamento e endogamia: observações sobre a organização social dos índios Maku. 1983. 387 f. Dissertação (Mestrado em Antropologia) - PPGA, UFRGS, Porto Alegre, RS, 1983.

POZZOBON, J. Parente et demographie chez les indiens Maku. 1991. 257 f. Tese (Doutorado em Antropologia). - Univ. Paris VII, Paris, 1991. 
Espaço Ameríndio

POZZOBON, J. Sociedade e improviso: estudo sobre a (des)estrutura social dos

índios Maku. Rio de Janeiro: Museu do Índio, 2011.

RAMOS, A., SILVERWOOD-COPE, P., \& OLIVEIRA, A. G. Patrões e clientes: relações intertribais no Alto Rio Negro. In: RAMOS, A. (Org.). Hierarquia e simbiose: relações intertribais no Brasil. São Paulo: Hucitec. 1980. p. 135-182.

RAMOS, D. Círculos de coca e fumaça: encontros noturnos e caminhos vividos pelos Hupd'äh. São Paulo: Hedra, 2018.

REID, H. Some aspects of movement, growth and change among the Hupdu Maku indians of Brazil. 1979. 405 f. Tese (Doutorado em Antropologia) - Univ. of Cambridge, Cambridge, 1979.

RIVET, P; TASTEVIN, C. Affinités du Makú et du Puinave. Jornal de la Societé des Américanistes, n.s. 12, p. 60-82, 1920.

SILVERWOOD-COPE, P. L. Os Makú: povo caçador do Noroeste da Amazônia. Brasília: UnB, 1990.

STRADELLI, E. Lendas e notas de viagem: a Amazônia de Ermanno Stradelli. São Paulo: Martins Fontes, 2009 (1890).

STRATHERN, M. Partial connections. New York: Rowman and Littlefield, 1991.

TERRIBLINI, M. Les Makús aux confins de l'Amazonie. Vevey-Suisse: Fondation Les Eglantines, 2000.

VIDAL, S. Kuwé Duwákalumi: The Arawak Sacred Routes of Migration, Trade, and Resistance. Ethnohistory, v.47, n. 3/4, p.635-667, 2000.

VIVEIROS DE CASTRO, E.; GOLDMAN, M. Slow Motions [Extended Remix]: Comments on a Few Texts by Marilyn Strathern. In: LEBNER, A. (Org.). Redescribing Relations. Strathernian Conversations on Ethnography, Knowledge and Politics. Oxford: Berghahn Books, 2017. p. 173-196.

WRIGHT, R. História indígena do Noroeste amazônico: hipóteses, questões e perspectivas. In: CARNEIRO DA CUNHA, M. (Org.). História dos índios no Brasil. São Paulo: Companhia das Letras, 1992. p. 253-266. 